\title{
RNA-seq highlights parallel and contrasting patterns in the evolution of the nuclear genome of fully mycoheterotrophic plants
}

\author{
Mikhail I. Schelkunov ${ }^{1 *}$ (D) Aleksey A. Penin ${ }^{1,2,3}$ and Maria D. Logacheva ${ }^{1,4,5^{*}}$
}

\begin{abstract}
Background: While photosynthesis is the most notable trait of plants, several lineages of plants (so-called full heterotrophs) have adapted to obtain organic compounds from other sources. The switch to heterotrophy leads to profound changes at the morphological, physiological and genomic levels.

Results: Here, we characterize the transcriptomes of three species representing two lineages of mycoheterotrophic plants: orchids (Epipogium aphyllum and Epipogium roseum) and Ericaceae (Hypopitys monotropa). Comparative analysis is used to highlight the parallelism between distantly related fully heterotrophic plants.

In both lineages, we observed genome-wide elimination of nuclear genes that encode proteins related to photosynthesis, while systems associated with protein import to plastids as well as plastid transcription and translation remain active. Genes encoding components of plastid ribosomes that have been lost from the plastid genomes have not been transferred to the nuclear genomes; instead, some of the encoded proteins have been substituted by homologs. The nuclear genes of both Epipogium species accumulated nucleotide substitutions twice as rapidly as their photosynthetic relatives; in contrast, no increase in the substitution rate was observed in H. monotropa.
\end{abstract}

Conclusions: Full heterotrophy leads to profound changes in nuclear gene content. The observed increase in the rate of nucleotide substitutions is lineage specific, rather than a universal phenomenon among non-photosynthetic plants.

Keywords: Ericaceae, Loss of photosynthesis, Mycoheterotrophic plants, Nuclear genome, Orchidaceae, RNA-seq, Sequencing

\section{Background}

The capability for photosynthesis is the iconic trait of plants and is of the highest importance to the biosphere. However, some plants, including several thousands of flowering plant species, obtain organic substances from sources other than photosynthesis $[1,2]$. These plants acquire organic compounds either from associated fungi (myco-heterotrophy) or by parasitizing other plants. Most of these species combine photosynthesis and heterotrophy, but several hundred species have totally lost photosynthetic ability and become fully heterotrophic. The acquisition of heterotrophic ability has occurred in the evolutionary history of plants more than 50 times $[1,2]$. The switch to full heterotrophy leads to profound changes at the phenotypic level

\footnotetext{
*Correspondence: shelkmike@gmail.com; maria.log@gmail.com ${ }^{1}$ Institute for Information Transmission Problems, Russian Academy of Sciences, Moscow, Russia

Full list of author information is available at the end of the article
}

(reduction of leaves, loss of green colour, reduction of the vegetation period) that are highly parallel in different lineages. The genotypic alterations that underlie these changes are for the most part unclear. The difficulty of cultivating heterotrophic plants under experimental conditions hampers classic genetic and physiological studies. Advances in DNA sequencing permit the application of a genomic approach to elucidate the genetic changes associated with heterotrophy.

Genetic and genomic studies of heterotrophic plants are currently focused on two aspects. The first is the interaction of parasitic plants with their hosts and their adaptations to parasitism (e.g., [3]. Extensive exchange of transcripts occurs between hosts and parasites [4]. On an evolutionary scale, a large number of horizontal gene transfer (HGT) events from hosts to parasites have been found in the organellar and nuclear genomes of parasitic plants $[5,6]$. A recent large-scale survey of HGT in 
Orobanchaceae showed that the number of these events correlates positively with the degree of heterotrophy [7]. The second aspect is the evolution of organellar (mainly plastid) genomes. As expected, the plastomes of heterotrophic plants are reduced in size due to the loss of genes related to photosynthesis, and may retain only $7.5 \%$ of the length of a typical plastome as in the parasitic plant Pilostyles aethiopica whose plastid genome is approximately 11 kilobase pairs (kbps) long versus approximately $150 \mathrm{kbps}$ in typical autotrophic plants [8]. Despite the high degree of reduction, the plastomes of non-photosynthetic plants retain genes whose products are involved in translation, specifically transfer RNAs, components of the plastid ribosome and two other genes, $a c c D$ and $c l p P$ (e.g., [8-12]). Although there are several considerations regarding the retention of the plastome, complete loss of the plastome is also apparently possible. At present, there are two known cases of such loss, one in Polytomella, a genus of unicellular algae [13], and one in the parasitic angiosperm Rafflesia lagascae [14], although alternative explanations are possible in the latter case, like a highly divergent sequence of the plastid genome or its low copy number per cell [15]. Much less information on the mitochondrial genomes of non-photosynthetic plants is available, although there are indications that these genomes are not as extensively reduced in size [16].

The changes in the nuclear genomes of non-photosynthetic plants have not been well studied. To date, the only work to deeply analyse the nuclear genomes of fully heterotrophic plants was performed in Orobanchaceae, where a fully heterotrophic species, Orobanche aegyptiaca, was compared with two of its relatives, one mixotroph with obligatory parasitism and one mixotroph with facultative parasitism [17]. Surprisingly, the authors found evidence for conservation of the pathways responsible for chlorophyll synthesis.

To obtain a more detailed understanding of the evolution of fully heterotrophic plants, in this work, we analyse the nuclear genomes of Epipogium aphyllum and E. roseum (Orchidaceae) and Hypopitys monotropa (Ericaceae) using transcriptome sequencing. These plants, though being very distantly related at phylogenetic level (they belong to the monocots and eudicots, correspondingly), are similar in their appearance (Fig. 1) and ecological characteristics. They are good models for studying the characteristics of fully heterotrophic plants since their plastomes are among the most reduced in size $[11,18]$ (19-35 Kb versus approximately $150 \mathrm{~Kb}$ in typical photosynthetic plants). Therefore, we expect that the nuclear genomes of these species may also differ profoundly from the genomes of photosynthetic plants and will therefore allow us to highlight characteristics that are specific to the genomes of fully heterotrophic species. The nuclear genomes of E. aphyllum and E. roseum were not studied previously. For $H$. monotropa there is an article, dedicated mostly to the analysis of its plastid genome, which also states that transcripts of some nuclear genes encoding parts of the plastid electron transport chain, photosystems I and II, and ATP-synthase were not found in the transcriptome [19].

\section{Methods}

\section{Sample collection, library preparation and sequencing}

Samples were collected in natural habitats of each species, in the middle of their flowering period. The identification of $E$. aphyllum and $H$. monotropa was carried out by $\mathrm{M}$. D. Logacheva and E. roseum - by M.S. Nuraliev. Dried specimen of $E$. roseum is deposited in the herbarium of vascular plants of the Komarov botanical institute (LE) and H. monotropa - in the herbarium of Lomonosov Moscow State University (MW). More detailed information on the specimens, including the place and time of collection was reported earlier by Schelkunov et al. [11] for E. aphyllum ("White Sea" sample) and E. roseum ("Vietnam 2" sample) and by Logacheva et al. [18] for $H$. monotropa. Immediately after collection aerial parts of plants were fixed in RNAlater (Qiagen, Netherlands). Prior to extraction the samples were homogenized in liquid nitrogen. RNA was extracted using Qiagen RNeasy Plant Mini kit (Qiagen, Netherlands) using manufacturer's instructions. The only modification was the addition of Plant RNA Isolation Aid (ThermoFisher Scientific, USA) to the lysis buffer. To allow the characterization of non-polyadenylated transcripts (e.g., plastid and mitochondrial) we performed depletion of ribosomal RNA using Ribo-Zero plant leaf kit (Illumina, USA). For $H$. monotropa one rRNA depleted and four polyA-RNA libraries were prepared, for Epipogium only rRNA depleted libraries, due to the limited availability of the material. All libraries were prepared using RNA Sample prep kit v. 2 (Illumina, USA) following manufacturer's instructions. The libraries were sequenced on Illumina HiSeq and Illumina MiSeq sequencing machines in paired-end mode. Detailed information on the libraries and sequencing settings, as well as links to on-line databases where the reads are deposited, is provided in Additional file 1: Table S1.

\section{Choice of datasets of photosynthetic plants}

To compare the fully heterotrophic species with typical photosynthetic plants, we obtained data from several RNA-seq experiments and from the genome assemblies of the plants that were available as of 2015. A sequenced transcriptome had to satisfy the following criteria to be used in our study:

1. At least 100 million RNA-seq reads should be sequenced. A study of the transcriptomes of two 

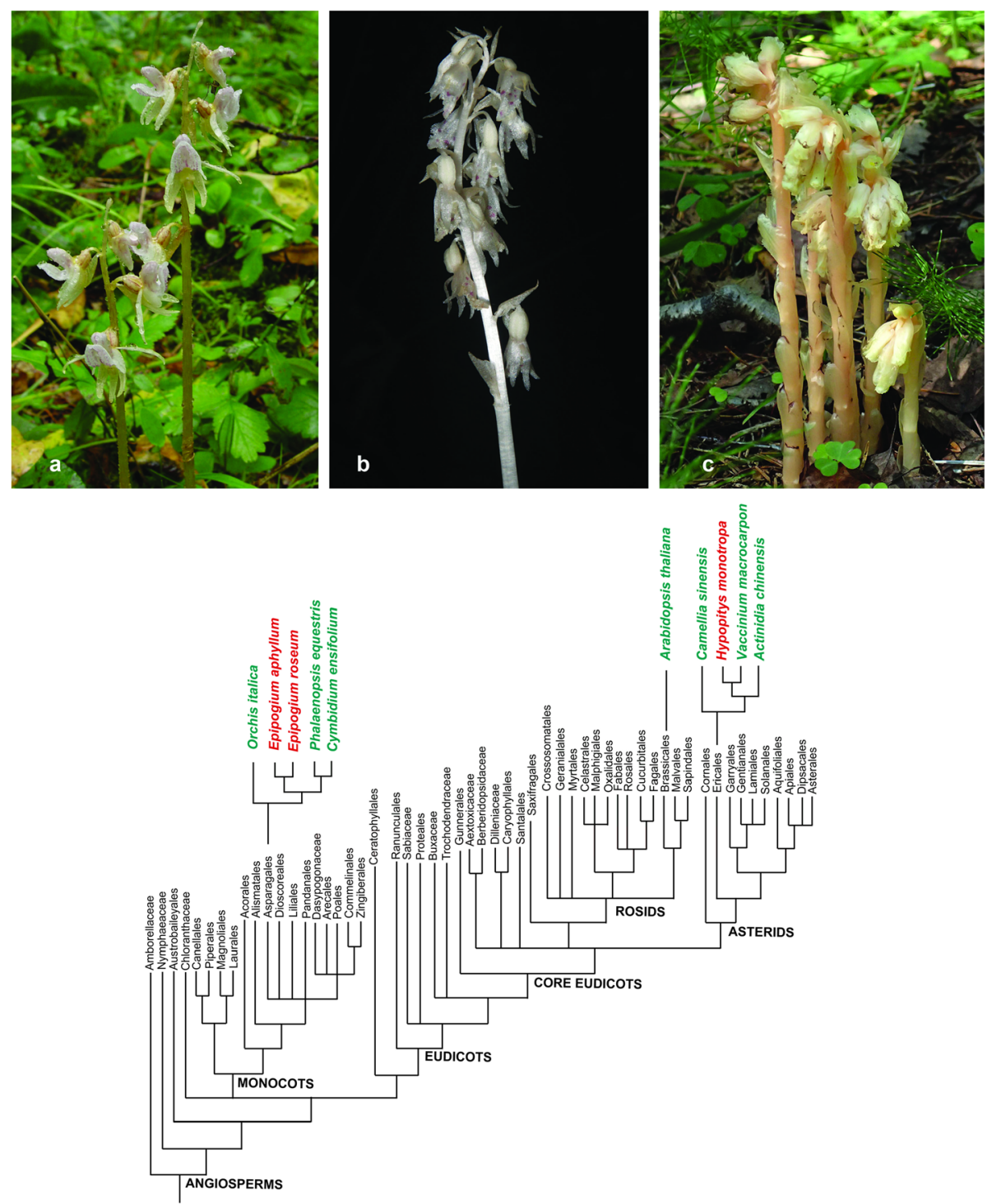

Fig. 1 General view and phylogenetic position of the studied species. Upper panel, a Epipogium aphyllum, b E. roseum, c Hypopitys monotropa. Lower panel: angiosperm phylogenetic tree (redrawn from APG II 2003). The insets demonstrate phylogenetic relationships between heterotrophic species (shown in red) and photosynthetic species (shown in green)

species of Geraniaceae suggests that the completeness of the assemblies does not increase highly when using more than 100 million of Illumina reads [20].

2. The sequencing should have been performed on Illumina sequencing machines, since they generate reads with the least number of sequencing errors compared to other technologies.

3. The sequenced transcriptome should belong to above-ground parts of a plant, preferably to the inflorescence. This facilitates the comparison with the transcriptomes of Epipogium and Hypopitys, for which inflorescences were sequenced. Using transcriptomes of some other parts, for example roots, could be inappropriate because they can contain a different set of expressed genes.

In view of these considerations, we chose six photosynthetic species, including three for comparison with Epipogium and three for comparison with H. monotropa. The names and sources of the datasets on photosynethetic plants are listed in Additional file 1: Tables S1 and S2. In the case of RNA-seq data, we assembled the transcriptomes using exactly the same methods that were used for the transcriptomes of Epipogium and Hypopitys. 


\section{Transcriptome assembly and postprocessing}

Reads were trimmed with Trimmomatic 0.32 [21]. Trimming involved the removal of sequencing adapters, bases with a Phred quality of less than 3 from both the $5^{\prime}$ and $3^{\prime}$ ends of reads, and bases from the $5^{\prime}$ ends of reads starting from a region with 5 consecutive bases with an average score of less than 10 (trimming with a sliding window). Additionally, reads that had average quality of less than 20 after trimming and reads that after trimming became shorter than 30 base pairs (bps) were removed. For species with several sequenced libraries reads were pooled. Assembly was performed using Trinity version r20140717 [22]. We utilized the option of digital normalization provided by Trinity, normalizing the read coverage to $50 x-$ this option highly reduces RAM and CPU usage while almost not affecting the assembly quality [23]. The minimum contig length was set to $100 \mathrm{bps}$ instead of the default value of $200 \mathrm{bps}$. After assembly, we performed filtration, removing minor isoforms, low-coverage transcripts and contamination. We defined major isoforms as the isoforms to which the highest number of reads (estimated using RSEM [24] in-built in Trinity) were mapped relative to other isoforms. After removing minor isoforms, we filtered low-coverage transcripts by mapping reads to contigs using CLC Assembly Cell 4.2 [25], with a requirement of at least $80 \%$ of read's length mapping with sequence identity at least $98 \%$, and retaining only transcripts with average coverage at least 3 reads per positions. Potential coding sequences (CDSs) in the transcripts were then determined using TransDecoder version r20140704 [23]. The criteria for considering an open reading frame (ORF) to be a potential CDS consisted not only of hexanucleotide frequencies, which are employed in TransDecoder by default, but also all ORFs that possessed domains from the Pfam-A or Pfam-B databases. The minimum CDS length was decreased from the default of 100 amino acids to 30 amino acids. When there were several potential CDSs from a transcript, only the longest one was taken. Then, to remove contamination, we performed BLASTP 2.2.29+ [26] alignment (maximum allowed e-value $10^{-5}$, word size 3 , the low-complexity filter switched off) of the translated CDS sequences against the NCBI (National Center for Biotechnology Information) NR database and against proteins of related plants whose genomes had been sequenced. A CDS was considered to represent contamination if the BLASTP match with the highest bit score was to a species that was not from Streptophyta (in terms of NCBI Taxonomy). Conversely, if the best match was to Streptophyta member or the sequence presented no BLASTP matches, the CDS was considered to belong to a plant. Statistical parameters of the assemblies, such as N50 values and the number of sequences longer than $1000 \mathrm{bps}$, were calculated using custom scripts after each filtering step described above. Estimation of the completeness of the assemblies was performed with CEGMA 2.5 [27]. To evaluate gene expression without contamination, we calculated FPKM (Fragments per kilobase per million reads mapped) values using RSEM for transcripts that contained CDSs that were determined not to have arisen from contamination. Minor isoforms of the transcripts were also used for the analysis; the FPKM values provided in Additional file 1: Table S10 are the sums of all gene isoforms.

The assembled transcripts are deposited in the Transcriptome Shotgun Assembly Database (TSA) with accessions provided in Additional file 1: Table S1. Additionally, the longest ORFs from the major isoforms of the transcripts, after the removal of low-coverage transcripts and contamination, are provided in Additional files 2, 3 and 4.

\section{Transcriptome annotation and gene ontology analysis}

Three types of annotations of the CDSs were performed. The first was the computation of 1-1 orthologs from the CDSs of each species by reciprocal alignment with Arabidopsis thaliana proteins from TAIR10 (The Arabidopsis Information Resource, 10th release) database [28] using BLASTP (parameters are the same as indicated above). Lists of 1-1 orthologs for $E$. aphyllum, E. roseum and $H$. monotropa are provided in Additional file 1: Tables S3, S4 and S5. Also we performed GO annotation using results of BLASTP alignment of all proteins against the NCBI NR (parameters as above) and annotated them with B2G4Pipe 2.5, a command-line wrapper for Blast2GO [29]. Then we assigned KEGG (Kyoto Encyclopedia of Genes and Genomes) Orthology identifiers to the CDSs with the GhostKoala server [30]. The orthogroups in the studied species were calculated separately for Orchidaceae and Ericales using OrthoMCL 2.09 [31] (inflation parameter 1.5).

For GO term enrichment analysis, we used a set of custom scripts written in Perl and R. Utilizing the results of the GO annotation performed with Blast2GO and a graph of GO terms [32], the scripts provide all GO terms corresponding to a gene, including terms that are paternal (i.e., with higher hierarchical levels) to those provided by Blast $2 \mathrm{GO}$. Comparison of the numbers of genes with specific GO terms between a pair of species was then performed via a series of Fisher's exact tests (one for each GO term). GO terms that were not assigned to any genes in either species were excluded from the analysis. After the Fisher's tests were performed, the scripts performed group comparisons between fully heterotrophic and photosynthetic plants for each GO term, by taking all $p$-values for each pairwise comparison between pairs of species within the group (Ericales or Orchidaceae). The scripts then conducted Bonferroni correction for multiple testing to evaluate the statistical significance of the differences between these groups separately for Orchidaceae and Ericales. 
Next, another round of correction for multiple hypothesis testing was performed, taking into account the fact that an individual Fisher's test was performed for each GO term. This correction was performed via the method of Benjamini-Yekutieli [33].

Since our goal was the analysis of nuclear genes, we excluded genes encoded in the plastid and mitochondrial genomes from the enrichment analysis by excluding all genes that were 1-1 orthologs of plastid and mitochondrial genes of Arabidopsis thaliana. Some plastid and mitochondrial transcripts may not have been present in the assemblies. To compensate for this, in Additional file 1: Table S10, we indicated a plastid gene as present in the plastome of a studied species not only when it was found through the 1-1 ortholog method, but also when it was present in the annotation of the plastome of that species provided in GenBank (accessions are provided in Additional file 1: Table S2). Because the plastome of Orchis italica is not available, we employed the plastome of Habenaria pantlingiana, the only species with a characterized plastome from subtribe Orchidiae, which includes O. italica.

\section{Analysis of substitution rates and selective pressure}

To estimate the average selective pressure and substitution rates in the genomes of the studied species, we concatenated the sequences of all genes from orthogroups containing exactly one gene from each species. The concatenated sequences were then aligned using TranslatorX 1.1 [34]. As a tool for the alignment of the amino acid sequences by TranslatorX, we used Muscle [35]. The topologies of the phylogenetic trees for Orchidaceae and Ericales were obtained from Peter Stevens' Angiosperm Phylogeny Website, version 14 [36]. dN/dS and substitution rate estimation was performed based on the alignment and the tree using PAML 4.8 [37], employing a branch model with free ratios, the Gy94_3 $3 \times 4$ codon model and removal of all columns with at least one gap in the alignment.

To compare the magnitude of the selective pressure acting on individual genes in heterotrophic and autotrophic plants, the sequences of the genes were aligned using TranslatorX and Muscle as described above, and $\mathrm{dN} / \mathrm{dS}$ ratios were calculated using PAML in the branch model. For the Orchidaceae, two calculations were performed. In the first calculation, one $\mathrm{dN} / \mathrm{dS}$ was allowed for the branches of autotrophic plants; another $\mathrm{dN} / \mathrm{dS}$ was allowed for the terminal branches of E. aphyllum and E. roseum; and a third $\mathrm{dN} / \mathrm{dS}$ was allowed for the branch of their common ancestor. The second calculation was performed allowing one $\mathrm{dN} / \mathrm{dS}$ for the common ancestor of E. aphyllum and E. roseum and a second $\mathrm{dN} / \mathrm{dS}$ for all other branches, including autotrophic species, E. aphyllum and E. roseum. The P-values for the difference in $\mathrm{dN} / \mathrm{dS}$ between the terminal branches of Epipogium and the branches of autotrophic species were calculated using the likelihood ratio test. Allowing an individual $\mathrm{dN} / \mathrm{dS}$ for the branch of the common ancestor of Epipogium was beneficial, as photosynthetic ability was lost on that branch, and it is unclear whether to group it with autotrophic or heterotrophic species. Similar calculations were performed for Ericales, allowing different $\mathrm{dN} / \mathrm{dS}$ ratios for the $H$. monotropa branch and other branches the first time and demanding a single $\mathrm{dN} / \mathrm{dS}$ for all branches the second time. Since H. monotropa was the only heterotrophic species from Ericales employed in this study, its terminal branch partially included its autotrophic ancestor. Thus, the values of $\mathrm{dN} /$ dS provided for H. monotropa in Additional file 1: Table S10 describe selective pressure partially before and partially after the loss of photosynthetic ability. $\mathrm{dN} / \mathrm{dS}$ was calculated only for genes that were present in all 5 species of Orchidaceae or in all 4 species of Ericales.

\section{Analysis of protein targeting to organelles}

To estimate the number of proteins targeted to various organelles, we predicted transit peptides using TargetP 1.1 [38] and DualPred [39]. Unlike TargetP, DualPred is also capable of predicting proteins that are dually targeted to mitochondria and plastids. TargetP classifies predictions into five "reliability classes", where the most confident predictions belong to the first class, and the least confident predictions belong to the fifth class. We considered a protein to be potentially targeted to an organelle if its transit peptide exhibited a reliability class of four or less. For DualPred, we considered a protein to be dually targeted to plastids and mitochondria if it presented a dual-targeting score of at least 0.5 , as suggested by the first author of DualPred in a personal communication. Prediction of transit peptides was performed only for proteins whose genes exhibited a completely assembled 5 '-end according to TransDecoder and were assigned at least one $\mathrm{GO}$ term.

To predict the targeting of ribosomal proteins, we utilized a more elaborate technique. It has been demonstrated that some proteins are dually targeted to plastids and mitochondria not because they have one transit peptide that allows them to enter both organelles, but because their mRNAs exhibit alternative translation start sites, resulting in proteins with different transit peptides [40]. To search for transit peptides that may originate from alternative translation, we truncated all of the ribosomal proteins under analysis before the first methionine occurring after the first 25 amino acids (as in [40] and performed TargetP and DualPred analyses for these shortened versions of the proteins as well. Additionally, all alternative isoforms of the ribosomal proteins were 
analysed. When DualPred suggested that a protein was dually targeted and TargetP suggested either plastid or mitochondrial targeting, we considered this to represent a non-contradictory prediction suggesting dual targeting.

The Pfam families to which the ribosomal proteins belonged were determined by aligning Arabidopsis thaliana proteins to all families from the Pfam database, version 31.0 [41], using the HMMER server [42]. The search was performed with the default parameters, and the family that was indicated by the web-service as the "Top Hit" was condidered to be the family this protein belongs to. To identify proteins that belonged to these families in E. aphyllum, E. roseum and H. monotropa, we conducted a search with hidden Markov models of these families using the hmmscan tool from HMMER package, version 3.1b1 [43]. The search was performed among all of the CDSs from transcripts, not only the longest ones, to make detection in polycistronic mitochondrial mRNAs possible. The queries in the search were the hidden Markov model (HMM) profiles of the ribosomal protein families. The subjects were the aforementioned CDSs translated to amino acids. The e-value threshold for a match to be considered significant was set to $10^{-5}$. Orthologous proteins in the photosynthetic species employed for comparison were determined as belonging to orthogroups (calculated by OrthoMCL as described above) that contained the proteins identified for $E$. aphyllum, E. roseum and H. monotropa.

To search for homologs of RECA which may function in plastids of the studied heterotrophic species, we aligned the hidden Markov model of RECA (PF00154 model in the Pfam database) to the CDSs, exactly as with did while searching for the ribosomal proteins. Putative transit peptides were predicted in the same way too.

\section{Graphic representation of results}

Phylogenetic trees were drawn with TreeGraph 2.9.2 [44]. Maps of metabolic and signalling pathways were built on the KEGG site [45] (accessed 22 October 2015).

\section{Results and discussion}

\section{Characteristics of transcriptome assembly}

The statistics of transcriptome assembly are provided in Table 1 (for details, see Additional file 1: Table S7). Simple statistical measures, such as N50 values and the mean contig length, were smaller than those in many studies involving transcriptome assemblies, mainly because we analysed contigs with a minimum length of $100 \mathrm{bps}$ instead of $200 \mathrm{bps}$ (the default cut-off in the Trinity assembler). Several genes of interest (for example, the plastid genes rpl32 and rpl36) are shorter than $200 \mathrm{bps}$, and use of the default cut-off would incur a risk of missing their transcripts. The assembly statistics were also biased by contamination. The symbiosis of mycoheterotrophic plants with fungi may be quite deep; for example, the rhizome of E. aphyllum has been described as "heavily and permanently infected" [46]. Despite the fact that we sequenced RNA from the above-ground parts of the plants, we observed a large number of bacterial and fungal transcripts in the assemblies (Additional file 5: Figure S1), especially in $E$. roseum, in which they represented $\sim 80 \%$ of contigs that we were able to taxonomically classify by BLAST. In $E$. aphyllum and $H$. monotropa, the corresponding values were approximately 10 and 5\%, respectively. This difference may reflect the correlation between soil microbiome biomass and climate (E. aphyllum and $H$. monotropa were collected from colder regions than $E$. roseum). Among the transcriptomes of photosynthetic plants used for comparison, the transcriptome of O. italica was also highly contaminated. The high amount of contamination reduces the number of reads belonging to true plant transcripts in E. roseum and O. italica. Nevertheless, we do not consider this a significant obstacle since E. aphyllum (which does not have a lot of contamination) and $E$. roseum are very close phylogenetically and similar gene content is expected in their genomes. Likewise, using $P$. equestris and C. ensifolium as two additional reference photosynthetic orchids compensates for a potentially poor assembly of the O. italica. Sequences originating from fungi and bacteria were

Table 1 Brief statistics of the transcriptome assemblies

\begin{tabular}{|c|c|c|c|c|c|c|}
\hline & \multicolumn{2}{|c|}{ Epipogium aphyllum } & \multicolumn{2}{|c|}{ Epipogium roseum } & \multicolumn{2}{|c|}{ Hypopitys monotropa } \\
\hline & All transcripts & $\operatorname{CDSs}^{\mathrm{a}}$ & All transcripts & $\operatorname{CDSS}^{\mathrm{a}}$ & All transcripts & $\operatorname{CDSS}^{\mathrm{a}}$ \\
\hline Number of sequences & 992,338 & 20,958 & $1,336,170$ & 19,026 & 217,166 & 13,276 \\
\hline Number of sequences longer or equal to 1000 bps & 39,403 & 4321 & 28,284 & 3259 & 33,560 & 5421 \\
\hline Total length of sequences & $290,947,719$ & $12,988,731$ & $321,048,790$ & $10,721,418$ & $116,614,033$ & $13,496,709$ \\
\hline N50 & 371 & 1173 & 257 & 990 & 1199 & 1470 \\
\hline Median length of sequences & 178 & 306 & 164 & 315 & 237 & 807 \\
\hline
\end{tabular}

${ }^{a}$ Here, the CDS is defined as the longest ORF in the major isoforms of the transcripts that were assigned at least one GO term (low-coverage transcripts and contaminating transcripts are not considered) 
discarded prior to further analysis. Estimation of the completeness of the assemblies based on the set of genes that are expected to be present in all eukaryotic genomes [27] showed that $>90 \%$ of these genes were at least partially assembled (Additional file 1: Table S8). Notably, the genomes were assembled less completely than the transcriptomes on average, with a median of $95.6 \%$ of the genes being assembled at least partially in the transcriptome assemblies, compared with $90.8 \%$ of the genes in the genome assemblies. These results show that, given sufficient coverage, RNA-seq is as good as complete genome sequencing in terms of the number of retrieved genes, while being less costly and using an assembly process that is computationally faster. It could however miss some genes expressed at very low levels, thus the results on gene loss based on transcriptome assemblies should be interpreted with more caution.

\section{Gene retention and reduction}

Plastid-targeted proteins carry specific amino acid sequences known as targeting signals or transit peptides that interact with the translocon system and enable the import of these proteins into plastids. Thus, we expected that in non-photosynthetic plants, the fraction of proteins with plastid-targeting signals relative to other proteins will be decreased. However, a comparison revealed a more complex situation. In Epipogium, the fraction of proteins targeted to plastids relative to the total number of proteins is approximately 2 times lower than in autotrophic orchids on average, whereas the fraction of proteins that are targeted to mitochondria or the endoplasmic reticulum is approximately the same. In contrast, in $H$. monotropa, the fraction of proteins targeted to plastids does not appear to be decreased. However, because the fraction of plastid-targeted proteins differs greatly between the two photosynthetic Ericales species that we used for comparison (Additional file 1: Table S9), these results should be treated with caution, as they may be biased by lineage-specific genome duplications and/or by differences in the quality of the assemblies. To obtain a deeper understanding of the patterns of gene reduction, we performed Gene Ontology (GO) enrichment analyses. GO analysis of Epipogium aphyllum and E. roseum versus three photosynthetic orchids revealed that the genes associated with 60 GO terms in Epipogium were underrepresented, while the genes associated with 38 terms were overrepresented, with $\mathrm{q}$-values $\leq 0.05$. All of the overrepresented GO terms are related to genes associated with mobile elements. Although the titles of these GO terms (like "RNA-dependent DNA replication" or "endoribonuclease activity") do not directly mention mobile elements, we checked several dozen random genes with these GO terms and verified by BLASTP alignment to the NCBI NR database that many of them are indeed genes of mobile elements. Some high-level (in terms of the Gene Ontology hierarchy) terms are overrepresented probably because they include low-level terms describing genes of mobile elements, for example the term "nucleobase-containing compound metabolic process" includes the term "RNA-dependent DNA replication". The presence of overrepresented GO terms related to mobile elements is presumably caused by methodological differences, as the Epipogium transcriptomes were sequenced without selection of polyadenylated transcripts, whereas the transcriptomes of Cymbidium ensifolium and O. italica represented polyA fractions. Thus, mobile elements whose RNAs are rarely polyadenylated (for example, like the mobile elements of the BARE family [47]), are expected to be overrepresented in Epipogium. In the genome of Phalaenopsis equestris, mobile elements are masked as repeats, producing a similar effect. Among the underrepresented GO categories, almost all were related to photosynthesis and plastids. The least underrepresented GO terms were general and difficult to interpret (e.g." "Single-organism metabolic process" and "Membrane"). The most underrepresented GO terms are listed in Table 2; for a complete list, see Additional file 1: Table S6.

GO enrichment analyses between $H$. monotropa and three photosynthetic Ericales showed similar results; 17 GO terms were overrepresented, and nine are underrepresented. The overrepresented terms were related to mobile elements, and the underrepresented terms were related to photosynthesis and plastids (Table 2; Additional file 1: Table S6).

Notably, we did not observe changes in the list of GO terms other than related to photosynthesis and plastids, despite dramatic differences in the morphology and physiology of the studied species. This finding indicates that these differences are controlled not at the level of the presence or absence of specific genes, but rather by the regulation of gene expression. To gain insight into this regulation, more detailed transcriptome data are required. Alternatively, these morphological and physiological changes may have originated from the disruption or loss of a small number of genes which do not produce statistically significant results in GO enrichment analysis.

The statistical analysis of GO terms is quite rough method and may not reflect differences at the level of individual genes. Thus, we also searched for orthologs of genes that are known to participate in processes occurring in the plastids in the model plant Arabidopsis thaliana.

As expected, genes related to photosynthesis have been lost from nuclear genomes of Epipogium and $H$. monotropa (Table 3). In particular, no nuclear-encoded components of the plastid electron transfer chain (PSB and PSA genes) were found, which is consistent with the absence of plastid-encoded $p s a$ and $p s b$ genes from the plastomes of all three species. Components of the light-harvesting antenna ( $L H C$ genes) were completely absent from $H$. monotropa; one such gene (LHCA4) was 
Table 2 GO terms showing the greatest differences in the fraction of genes between mycoheterotrophic species and their photosynthetic relatives

\begin{tabular}{|c|c|c|c|c|}
\hline \multicolumn{5}{|c|}{ Epipogium compared with photosynthetic orchids } \\
\hline GO term & $\begin{array}{l}\text { Type of } \\
\text { GO term }\end{array}$ & $\begin{array}{l}\text { Median number of genes with } \\
\text { this } \mathrm{GO} \text { term in Epipogium } \\
\text { aphyllum and Epipogium roseum }\end{array}$ & $\begin{array}{l}\text { Median number of } \\
\text { genes with this } \mathrm{GO} \text { term } \\
\text { in photosynthetic orchids }\end{array}$ & $\begin{array}{l}\text { Median ratio of fractions between } \\
\text { Epipogium aphyllum and Epipogium } \\
\text { roseum versus photosynthetic orchids }{ }^{a}\end{array}$ \\
\hline $\begin{array}{l}\text { chlorophyll } \\
\text { binding }\end{array}$ & $\begin{array}{l}\text { molecular } \\
\text { function }\end{array}$ & 0.5 & 34 & 0.011 \\
\hline $\begin{array}{l}\text { photosynthesis, } \\
\text { light harvesting }\end{array}$ & $\begin{array}{l}\text { biological } \\
\text { process }\end{array}$ & 1 & 23 & 0.035 \\
\hline photosystem I & $\begin{array}{l}\text { cellular } \\
\text { compartment }\end{array}$ & 2 & 38 & 0.041 \\
\hline $\begin{array}{l}\text { plastid thylakoid } \\
\text { lumen }\end{array}$ & $\begin{array}{l}\text { cellular } \\
\text { compartment }\end{array}$ & 1.5 & 31 & 0.041 \\
\hline $\begin{array}{l}\text { plastid thylakoid } \\
\text { membrane }\end{array}$ & $\begin{array}{l}\text { cellular } \\
\text { compartment }\end{array}$ & 55.5 & 201 & 0.20 \\
\hline $\begin{array}{l}\text { photosynthesis, } \\
\text { light reaction }\end{array}$ & $\begin{array}{l}\text { biological } \\
\text { process }\end{array}$ & 50 & 174 & 0.22 \\
\hline plastid thylakoid & $\begin{array}{l}\text { cellular } \\
\text { compartment }\end{array}$ & 89 & 275 & 0.25 \\
\hline $\begin{array}{l}\text { photosystem II } \\
\text { assembly }\end{array}$ & $\begin{array}{l}\text { biological } \\
\text { process }\end{array}$ & 28 & 93 & 0.25 \\
\hline photosynthesis & $\begin{array}{l}\text { biological } \\
\text { process }\end{array}$ & 125 & 294 & 0.35 \\
\hline $\begin{array}{l}\text { organelle } \\
\text { subcompartment }\end{array}$ & $\begin{array}{l}\text { cellular } \\
\text { compartment }\end{array}$ & 203.5 & 403 & 0.38 \\
\hline \multicolumn{5}{|c|}{ Hypopitys monotropa compared with photosynthetic Ericales } \\
\hline GO term & Type of GO term & $\begin{array}{l}\text { Number of genes } \\
\text { with this GO term } \\
\text { in H. monotropa }\end{array}$ & $\begin{array}{l}\text { Median number of genes } \\
\text { with this } \mathrm{GO} \text { term in } \\
\text { photosynthetic Ericales }\end{array}$ & $\begin{array}{l}\text { Median ratio of fractions } \\
\text { between } H \text {. monotropa versus } \\
\text { photosynthetic Ericales }\end{array}$ \\
\hline $\begin{array}{l}\text { plastid thylakoid } \\
\text { membrane }\end{array}$ & $\begin{array}{l}\text { cellular } \\
\text { compartment }\end{array}$ & 51 & 247 & 0.34 \\
\hline $\begin{array}{l}\text { photosynthesis, } \\
\text { light reaction }\end{array}$ & biological process & 51 & 243 & 0.37 \\
\hline plastid thylakoid & $\begin{array}{l}\text { cellular } \\
\text { compartment }\end{array}$ & 80 & 341 & 0.39 \\
\hline photosynthesis & biological process & 97 & 347 & 0.47 \\
\hline $\begin{array}{l}\text { tetrapyrrole } \\
\text { binding }\end{array}$ & molecular function & 136 & 395 & 0.57 \\
\hline plastid & $\begin{array}{l}\text { cellular } \\
\text { compartment }\end{array}$ & 1051 & 2177 & 0.81 \\
\hline $\begin{array}{l}\text { oxidation-reduction } \\
\text { process }\end{array}$ & biological process & 1122 & 2256 & 0.83 \\
\hline $\begin{array}{l}\text { single-organism } \\
\text { process }\end{array}$ & biological process & 6479 & 11,495 & 0.94 \\
\hline
\end{tabular}

GO terms that are similar to each other, such as "plastid thylakoid lumen" and "chloroplast thylakoid lumen", are combined here

${ }^{a}$ The fraction of genes with a specific GO term is the number of genes with that GO term in a species divided by the total number of genes with GO terms in that species. The median ratio of fractions is a measure of the difference in the numbers of genes with a specific GO term between two groups of species, calculated as a median value among all pairwise comparisons in which the first member in a pair comes from the first group, and the second member of the pair comes from the second group

present in the E. aphyllum transcriptome, but its expression (measured in FPKM) was 7-25-fold lower than in photosynthetic orchids. Nevertheless, this gene exhibited a full-length open reading frame that has evolved under negative selection ( $\mathrm{dN} / \mathrm{dS} 0.11)$. Since the product of this gene participates in chlorophyll binding, its retention may be in some way related to the retention of chlorophyll synthesis in Epipogium, as described below. Additionally, as shown in Additional file 1: Table S10, a few transcripts of genes that encode proteins in the plastid electron transfer chain were found in the transcriptomes of Epipogium aphyllum, E. roseum and H. monotropa. 
Table 3 Number of selected photosynthesis-related nuclear genes and nuclear genes encoding proteins involved in plastid functions other than photosynthesis in Epipogium aphyllum and photosynthetic orchids as well as Hypopitys monotropa and photosynthetic Ericales

\begin{tabular}{lllll}
\hline Genes & $\begin{array}{l}\text { Number in E. } \\
\text { aphyllum }\end{array}$ & $\begin{array}{l}\text { Median number in } \\
\text { photosynthetic orchids }\end{array}$ & $\begin{array}{l}\text { Number in H. } \\
\text { monotropa }\end{array}$ & $\begin{array}{l}\text { Median number in } \\
\text { photosynthetic Ericales }\end{array}$ \\
\hline $\begin{array}{l}\text { Photosynthesis-related } \\
\text { Components of photosystem I }\end{array}$ & 0 & 9 & 0 & 8 \\
$\begin{array}{l}\text { Components of photosystem II } \\
\text { Components of electron transfer chain }\end{array}$ & 0 & 9 & 0 & 8 \\
$\begin{array}{l}\text { (others than PSI and PSII) } \\
\text { Light-harvesting complex }\end{array}$ & 1 & 5 & 0 & 8 \\
$\begin{array}{l}\text { Calvin cycle } \\
\text { Sigma subunits of PEP and PEP-associated } \\
\text { proteins }\end{array}$ & 10 & 10 & 0 & 21 \\
Plastid ATP synthase & 0 & 20 & 14 & 14 \\
Non-photosynthesis-related & 0 & 14 & 1 & 3 \\
Plastid ribosome & & 3 & 0 & 31 \\
Clp subunits & 33 & 34 & 31 & 10 \\
ACC subunits & 11 & 12 & 10 & 18 \\
Plastid translocon & 5 & 6 & 4 & 11 \\
\hline
\end{tabular}

All of the observed sequences were shorter than $50 \%$ of the length of their orthologs in photosynthetic plants and are likely to be pseudogenes. The apparent partial conservation of enzymes in the Calvin cycle is due to that some of these enzymes are involved in metabolic processes that are not related to photosynthesis, e.g., glycolysis. Many genes that encode Calvin cycle enzymes belong to small gene families (e.g., GAPDH, PGK, TKL, $T P I)$ in which different members encode proteins that exhibit the same enzymatic activity (isoenzymes) but show different cellular localizations and act in different pathways. For example, the GAPDH and TPI proteins function in both glycolysis (cytosolic isoenzymes) and the Calvin cycle (plastidic isoenzymes). We assume that most of the transcripts corresponded to cytosolic isoenzymes. Consistent with this assumption, 8 of 10 of the transcripts found in Epipogium and 7 of the 14 transcripts found in H. monotropa did not have plastid-targeting signals. Most of the transcripts that did not have plastid-targeted signals have the $5^{\prime}$-ends of their CDSs completely assembled (according to the TransDecoder predictions), so we don't suppose this to be a result of misassembly. The transcripts with plastid-targeting signals (TKL, RPI) exhibit additional functions in plastids that are not related to the Calvin cycle. Expression of genes encoding proteins that act exclusively in photosynthesis (e.g., rbcS, SBPase) was absent. The nuclearencoded components of plastid ATP synthase have been completely lost, as well as the plastid-encoded components. The sigma subunits of plastid-encoded RNA polymerase (PEP) and PEP-associated proteins have also been lost. PEP is involved in the transcription of genes related to photosynthesis, unlike nuclear-encoded RNA polymerase (NEP), which mainly transcribes plastid genes that are unrelated to photosynthesis [48]. The redox-sensitive components of the plastid translocon, which is the system responsible for the import of proteins from the cytoplasm to plastids, have also been lost, with the exception of TIC32 of Hypopitys. This was expected, since the redox-sensitive components of the plastid translocon are thought to be regulated by redox signals from photosynthesis [49]. Transcripts encoding some components of the plastid translocon (as well as some other proteins analysed in the Additional file 1: Table S10) which are present in $A$. thaliana are absent in all studied Orchidaceae and Ericales. This indicates that not all cases of gene absence in Epipogium and Hypopitys should be ascribed to the loss of photosynthesis.

In contrast to genes encoding proteins that are necessary for photosynthesis, genes that are responsible for other functions of plastids have been retained (Table 3). In particular, components of clp-protease and acetyl-CoA carboxylase whose counterparts (clpP and accD) are encoded in the plastome have been retained. Consistent with this finding, NEP, which transcribes genes not related to photosynthesis, has been retained in both species, as have most components of the plastid ribosome (but see the discussion below). We also found transcripts of most proteins responsible for the replication and repair of the plastome. However, this situation is more complex because many of these proteins are targeted not only to plastids but also to mitochondria and the nucleus, and information on these proteins is sometimes inconsistent 
between different experiments $[50,51]$. A protein responsible for recombination and repair which we observed in almost all photosynthetic species of comparison but did not observe in all heterotrophic species is RECA1. The search for its homologs suggests that there are no plastid-targeting homologs of RECA in E. aphyllum and $E$. roseum. There is one homolog in $H$. monotropa for which predictions of TargetP and DualPred are contradictory, with TargetP suggesting no transit peptide and DualPred suggesting plastid targeting. As RECA participates in plastid recombination and repair (reviewed in [52]) the loss of RECA may explain both the increase in the substitution rate of the plastid genomes and the increase in their AT-content [11, 18], as gene conversion in plastids is GC-biased [53-55].

As shown above, the genomes of Epipogium and $H$. monotropa encode a number of proteins that must be imported into plastids. Accordingly, the components of the plastid translocons for both the outer- and inner-envelope membranes must be retained. Recent studies in A. thaliana have shown that the plastid-encoded protein ycf1 (TIC214) plays an essential role in plastid translocation and that it acts at the inner membrane [56]. However, the $y c f 1$ gene is absent from both the Epipogium and H. monotropa plastomes. A transcript similar to $y c f 1$ was only found in the transcriptome assembly of E. aphyllum, in which it carried a signal for targeting of the protein to mitochondria. Homologs of TIC100 and TIC56, which encode proteins that interact with Ycf1 within the TIC complex, were also absent from all three species. It should be noted that Ycf1 and its interacting proteins are also absent from several photosynthetic species, including grasses and Vaccinium macrocarpon, which raises a question regarding the universality of the function of Ycf1 [57]. The current model of TIC postulates the existence of two complexes. The first, referred to as the "photosynthetic-type" complex, consists of Ycf1, TIC56, TIC100 and TIC20-I and is a major TIC complex that functions in most land plants to import proteins involved in photosynthesis. The second complex is a "non-photosynthetic-type" complex, which imports proteins that are not related to photosynthesis [58]. It has been hypothesized that the switch from the major to the alternative system of protein import occurred in grasses $[58,59]$ and that the major system then degraded. The pattern of gene loss and retention observed in Epipogium and $H$. monotropa suggests that this could also be the case in these species. The existence of two complexes, one of which mainly imports photosynthetic proteins, while the other is non-photosynthetic, has also been postulated for the outer translocon TOC [58, 59]. Epipogium and $H$. monotropa possess orthologs of TOC proteins, but not a complete set (Table 2), suggesting that only one of these complexes is retained in these plants.

Annotation of the transcriptomes using the KEGG database of biological pathways revealed reductions in the number of genes associated with several other pathways, some of which are common to Epipogium and H. monotropa, while others are lineage-specific (Additional file 6: Figure S2, Additional file 7: Figure S3, Additional file 8: Figure S4 and Additional file 9: Figure S5). For example, a reduction in the number of proteins involved in light reception and circadian rhythms was observed; although this reduction was found in Epipogium as well as in Hypopitys, it was notably different in these fully heterotrophic plants (Additional file 6: Figure S2). In particular, Epipogium appears to lack genes encoding the photoreceptors phytochrome B and cryptochrome, whereas $H$. monotropa lacked several proteins (LHY, ZTL and GI) that regulate the circadian clock. The absence of these proteins may be related to the distinctive lifestyles of these plants, which spend most of their life cycle completely underground and appear above-ground only for several weeks during blossoming [60-62], and may therefore have different requirements for the regulation of circadian rhythms than typical autotrophic plants. However, both Epipogium and H. monotropa have retained essential elements of circadian clock regulation (HY5, ELF3), photoreceptor phytochrome A and proteins interacting with them (PIF, COP1), indicating that the core proteins that regulate plant development under the influence of light have been conserved. In addition, we found a reduction in the number of genes associated with the carotenoid (Additional file 7: Figure S3) biosynthesis pathway. As carotenoids are a component of light-harvesting antennae, the reduction in the number of genes related to carotenoid biosynthesis is presumably linked to the disappearance of photosynthesis. The pathway for phylloquinone synthesis is lost completely, while the pathway for plastoquinone synthesis persists (Additional file 8: Figure S4). Two functions of phylloquinone are known, namely it participates in the plastid electron-transfer chain and also aids in forming disulphide bond in PsbO [63]. As $\mathrm{PsbO}$ is a protein involved in photosynthesis, phylloquinone is dispensable in non-photosynthetic plants. Plastoquinone is a part of the plastid electron-transfer chain, but also it has other functions, for example it acts as an antioxidant [64], mediates stress response [65] and participates in synthesis of some plant hormones $[66,67]$. This may explain the retention of the plastoquinone synthesis pathway.

Another contrasting characteristic was the retention of the chlorophyll $a$ synthesis pathway in Epipogium, whereas only the gene responsible for the first step in this pathway has been retained in H. monotropa (Fig. 2). That gene (ALB1) codes for a protein which works in a complex with two other proteins (CHLI and GUN5) whose transcripts are not found in the transcriptome of $H$. monotropa. Thus, even the first reaction of the chlorophyll synthesis pathway is probably not accomplished in $H$. monotropa. The $\mathrm{dN} / \mathrm{dS}$ of $A L B 1$ in $H$. monotropa is significantly higher than in 


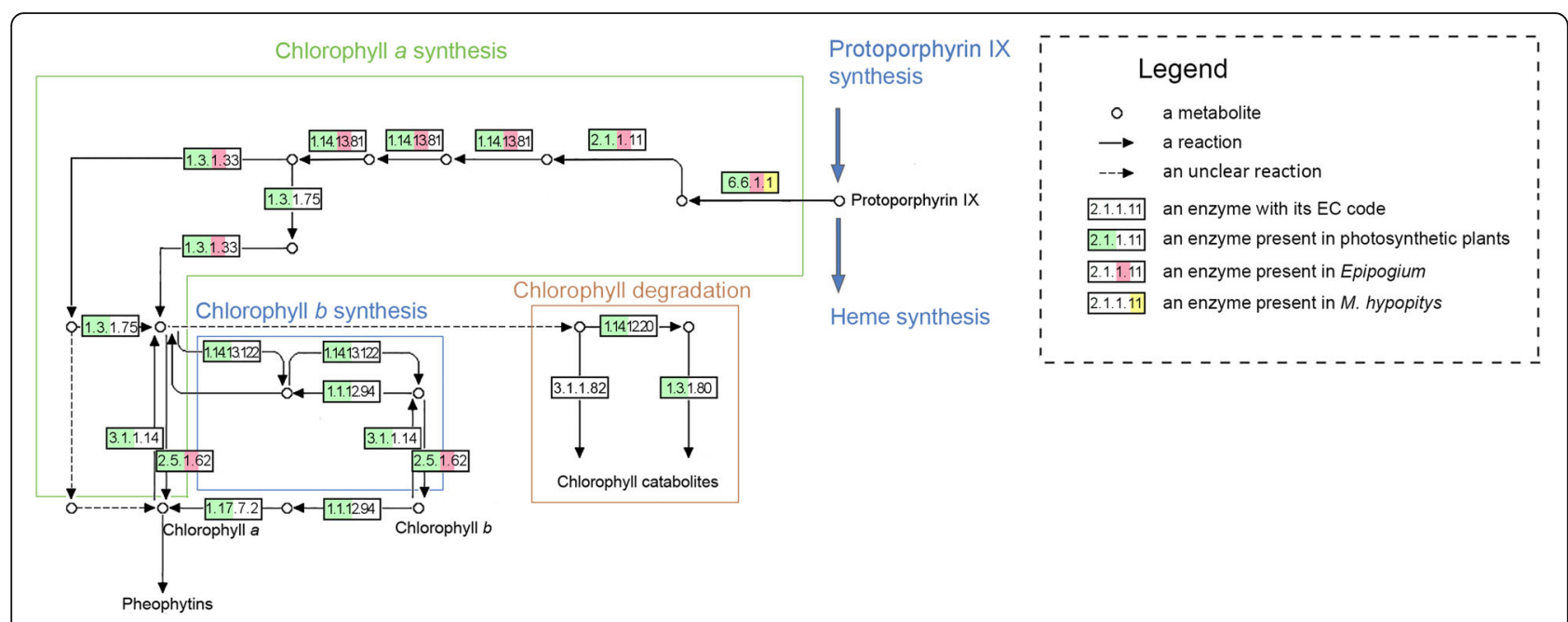

Fig. 2 Map of the chlorophyll metabolism pathway showing proteins present in Epipogium, Hypopitys monotropa and green plants. A protein is depicted as present in a specific plant group if its transcript was observed in a transcriptome of at least one species of that group

autotrophic Ericales ( $p$-value of 0.02 by the likelihood ratio test), showing a value of 0.27 in $H$. monotropa versus 0.11 in its autotrophic relatives. As the value in $H$. monotropa is lower than 1 , negative selection on this gene may have disappeared only recently, or, alternatively, this gene may still have some unknown function. Among the 5 considered genes in Epipogium, only 1 showed increased $\mathrm{dN} / \mathrm{dS}$ with a significant $\mathrm{p}$-value $(<0.05$ by the likelihood ratio test with Bonferroni correction). The mean dN/dS for these 5 genes in Epipogium was only slightly higher than the mean in its photosynthetic relatives, at 0.11 versus 0.05 , respectively (Additional file 1: Table S10). However, all of the genes in this pathway were expressed at levels many times lower than in photosynthetic species (Additional file 1: Table S10). Chlorophyll $a$ could theoretically be synthesized in Epipogium, where it may act in cellular processes that are unrelated to photosynthesis. Chlorophyll $a$ has been found in many heterotrophic plants via chromatography [68] (notably, among these species is Monotropa uniflora, a close relative of $H$. monotropa); transcriptome sequencing in parasitic Orobanche aegyptiaca has also demonstrated the presence of genes responsible for chlorophyll $a$ synthesis, with no signs of relaxed selection [17]. It has been shown that in $A$. thaliana, pheophorbide $a$, a product of chlorophyll $a$ catabolism, causes cell death in a light-independent manner [69, 70]. Conservation of this mechanism in Arabidopsis and non-photosynthetic plants could explain the conservation of the chlorophyll $a$ synthesis pathway.

Despite the differences discussed above, Epipogium and $H$. monotropa show striking parallelism in the reduction of their nuclear genes, considering that these plants lost autotrophic ability independently and that they diverged approximately 150 million years ago [71]. Quantitative estimates of this parallelism can be biased by differences in assembly quality and by lineage-specific gene losses that are not related to heterotrophy. To obtain an unbiased estimate, we considered only the genes that presented one-to-one orthologs in the Arabidopsis genome and were found in all 6 photosynthetic species used for comparison (4888 genes in total). Among these genes, 818 were absent in $E$. aphyllum, and 745 were absent in H. monotropa. In E. roseum, 996 genes were absent, which presumably reflects the lower quality of the assembly obtained for this species (Fig. 3). For E. aphyllum and E. roseum, the overlap between the lost genes was $67 \%$, whereas for E. aphyllum and $H$. monotropa, it was $49 \%$, and for E. roseum and $H$. monotropa, it was $45 \%$. If the losses occurred randomly, we would expect a much lower $(\sim 16 \%)$ percentage of common losses.

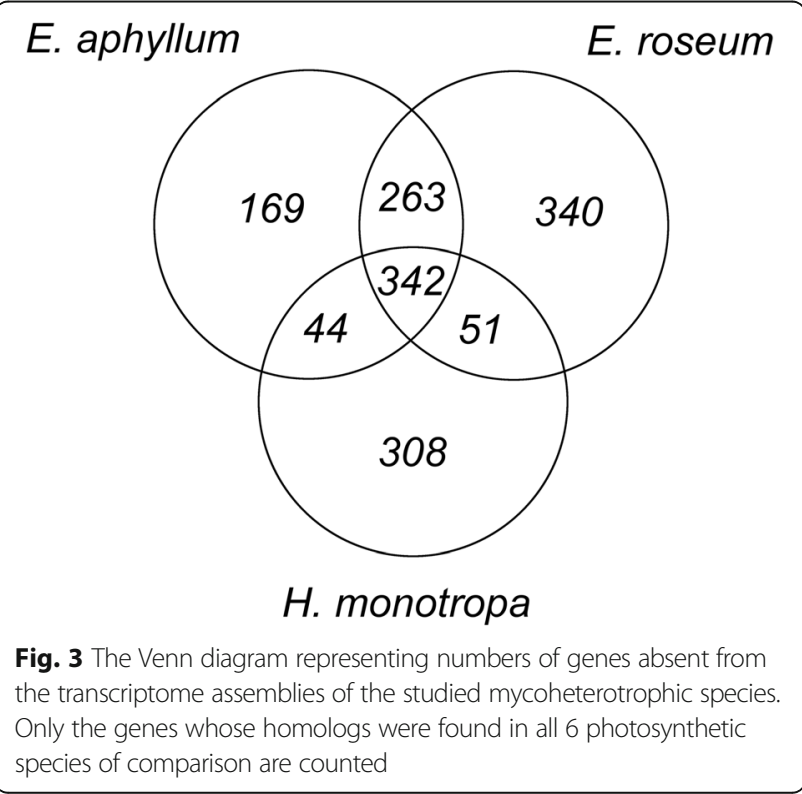


According to the hypergeometric test, the $p$-value for the null-hypothesis that losses are uncorrelated was < $10^{-100}$ for both the E. aphyllum/H. monotropa and $E$. roseum/H. monotropa pairs.

\section{Substitution rates}

Variation in substitution rates is a phenomenon that is widely observed in plants (e.g., [72]. In particular, it has been found that in parasitic plants, the substitution rate is increased not only in plastome, as expected for heterotrophic plants, but also in nuclear and mitochondrial genomes [73]. Concerning mycoheterotrophic plants, information on substitution rates is mostly limited to plastomes, which show increased substitution rates with only rare exceptions $[9,74]$. Our previous studies of Epipogium and $H$. monotropa indicated that the substitution rate in plastid genes, at both synonymous and in non-synonymous sites, was increased in comparison to the completely autotrophic relatives of these species, but at different levels (approximately 20 and 2.5 times respectively) [11, 18]. Characterization of transcriptome sequences allowed us to test whether this increase was confined to plastid genes. To calculate the substitution rate in the nuclear genomes, we used concatenated sequences of genes from orthogroups containing exactly one gene in each species. There were 4479 and 2547 of these orthogroups in Orchidaceae and Ericales, respectively. The substitution rates in both Epipogium species were approximately two times higher than the substitution rates in their photosynthetic relatives. The rates of non-synonymous and synonymous substitutions accumulation in Epipogium were increased proportionally (Additional file 10: Figure S6, Additional file 11: Figure S7 and Additional file 12: Figure S8). In contrast, the substitution rate in H. monotropa was not increased (Fig. 4).

The synonymous substitution rate (dS) estimate may be incorrect in cases where dS is large, due to saturation. However, the saturation starts to manifest itself on branches where dS is higher than 0.5 [75], thus the saturation is unlikely to spoil our estimates of $\mathrm{dS}$ and $\mathrm{dN} / \mathrm{dS}$.

PAML estimates may also be biased when analyzing sequences with different GC-content (confirmed in a personal communication with Ziheng Yang, the author of PAML). Nevertheless, the values of GC-content of the studied species differ by at most several percent (see the Additional file 1: Table S11) and we do not consider the difference as a source of a potential problem.

\section{Composition of the plastid ribosome}

The proteins of the plastid ribosome are encoded in both the plastid and nuclear genomes. For example, in Arabidopsis thaliana, 21 plastid ribosomal proteins are encoded by the plastome, and 36 are encoded by the nuclear genome. In all fully heterotrophic plants with highly reduced plastomes, some ribosomal genes are missing; Pilostyles aethiopica, in which only two ribosomal protein genes are retained, represents the most extreme known case [8]. This raises the question of how ribosomes are able to function in these species. There are three possibilities. First, some proteins of the plastid ribosome may simply be non-essential, and their loss may not severely affect ribosome function [76], although this does not explain such extreme cases of reduction. Second, since the transfer and integration of plastid DNA into the nucleus exists in plant cells, functional copies of plastid genes can arise in the nuclear genome. There are examples in which the products of such nuclear copies are targeted to plastids and function as a part of the plastid ribosome, while the corresponding gene having been lost from the plastome [77-79]. Third, components of mitochondrial ribosomes can be dually targeted to both plastids and mitochondria [80, 81]. In E. aphyllum [11], 7 ribosomal protein genes (rpl20, rpl22, rpl23, rpl32, rpl33, rps15, rps16) have been lost from the plastome; in $E$. roseum 6 of these 7 genes, but not rpl20, have been lost. Regarding $H$. monotropa, we previously considered rps19 and rpl22 to be pseudogenes [18] due to the presence of a
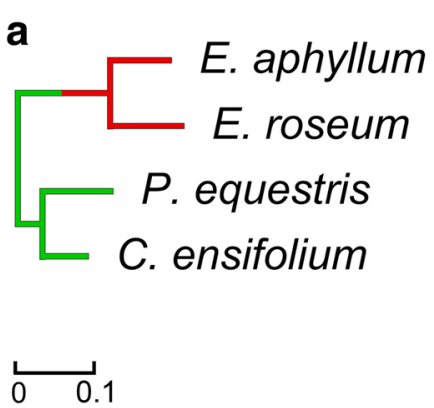
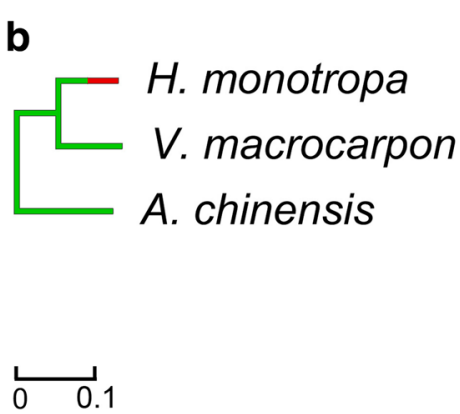

Fig. 4 Substitution rates in nuclear genes of Epipogium (a) and Hypopitys monotropa $(\mathbf{b})$. The branch lengths denote the number of nucleotide substitutions per position. Branches corresponding to non-photosynthetic species are indicated in red, and those corresponding to photosynthetic species are indicated in green. Branches in which a transition from a photosynthetic to a non-photosynthetic lifestyle occurred are indicated half in green and half in red. Orchis italica and Camellia sinensis, which are employed as outgroups in (a) and (b), respectively, are not shown, since the substitution rate of an outgroup cannot be evaluated 
111-bps insertion in the former and a nonsense mutation that shortens the length of the product by $17 \%$ in the latter. However, because these genes are transcribed and exhibit $\mathrm{dN} / \mathrm{dS}$ values close to those of the species' photosynthetic relatives (Additional file 1: Table S10), we assume that they are functional genes. Two genes, rps15 and rps16, were completely absent from the plastome of $H$. monotropa. We do not observe any transcripts with high similarity to these plastid genes in the transcriptomes of E. aphyllum, $E$. roseum or $H$. monotropa. Thus, the loss of these genes from the plastome is unlikely to be compensated by transfer of plastid sequences to the nuclear genome.

Instead, we found that several transcripts that are not 11 orthologs of plastid-encoded ones but have more distant homology to them encode proteins that can be imported into plastids. This is the case for Rpl23 and Rps15 in E. aphyllum and Rps15 in H. monotropa. Additionally, for several proteins, the predictions made with TargetP and DualPred, two tools that we used for target prediction, were contradictory. Specifically, for a homolog of Rpl32 in E. aphyllum and homologs of Rpl23, Rps15 and Rps16 in E. roseum, plastid targeting was predicted by only one of the two tools. In all cases except for Rpl23 of E. aphyllum, analysis of the transit peptides of the homologs in the photosynthetic relatives of these species suggested that these proteins were already targeted to plastids prior to the divergence of non-photosynthetic and photosynthetic species, which may have facilitated the loss of the respective plastid genes. Some of the aforementioned proteins are predicted to be targeted solely to plastids, and some are predicted to be dually targeted to plastids and mitochondria (for details see Additional file 1: Table S12).

To determine whether the genes whose products may serve to replace the lost ribosomal proteins are encoded in mitochondrial or nuclear genomes, we used TBLASTN to align the proteins against contigs produced during the assembly of the plastomes of E. aphyllum and H. monotropa in our earlier studies $[11,18]$ respectively). We did not observe the sequences of those genes in the mitochondrial contigs and therefore conclude that they are located in the nuclear genomes.

\section{Conclusions}

In this study, we analysed and compared the transcriptomes of the mycoheterotrophic plants Epipogium aphyllum, E. roseum and Hypopitys monotropa. Despite the fact that Epipogium and H. monotropa are very distantly related, belonging to the monocots and eudicots respectively, and that these species lost photosynthesis independently, we observed a remarkable level of parallelism involving the reduction and retention of similar functional groups of genes. Among the observed differences were a more profound reduction in the chlorophyll $a$ synthesis pathway in $H$. monotropa and an increased substitution rate in
Epipogium. Overall, since there are several hundred fully heterotrophic species of flowering plants [1], with many cases of independent transitions to fully heterotrophic lifestyle, it is necessary to sequence and analyse more fully heterotrophic species in addition to Epipogium, H. monotropa and Orobanche aegyptiaca to predict whether this parallelism is universal. Significant help in this determination may be provided by the "1000 Plants Project" [82], in which the sequencing of many fully heterotrophic and mixotrophic species is being performed. The question that remains unanswered in this study is the mode of gene loss - did it occur through deletions of large regions carrying photosynthesis-related genes, or through the accumulation of mutations in the protein-coding and regulatory elements of these genes? We expect that characterization of the nuclear genomes of non-photosynthetic plants will fill this gap.

\section{Additional files}

\begin{abstract}
Additional file 1: Table S1. Information on transcriptome data. Table S2. Sources of genome sequences. Table S3. List of 1-1 orthologs between Arabidopsis thaliana and Epipogium aphyllum. Table S4. List of 1-1 orthologs between Arabidopsis thaliana and Epipogium roseum. Table S5. List of 1-1 orthologs between Arabidopsis thaliana and Hypopitys monotropa. Table S6. Complete list of GO terms for which the fractions of genes differed significantly among Epipogium, Hypopitys monotropa and their photosynthetic relatives. Table S7. Detailed statistics of the transcriptome assemblies. Table S8. Analysis of the completeness of the assemblies. Table S9. Proportions of genes whose products are targeted to various organelles relative to the total numbers of genes in the species according to TargetP analysis. Only genes with complete $5^{\prime}$ ends and at least one assigned GO term are considered. Table S10. Presence of genes of interest in the studied species and selective pressures acting on them. Table S11. GC-content of concatenated genes' sequences. Table S12. Results of a search for possible substitutes for ribosomal proteins whose genes have been lost from the plastomes of Epipogium and Hypopitys monotropa. (XLSX 5745 kb)
\end{abstract}

Additional file 2: Longest open reading frames from major isoforms of the transcripts of Epipogium aphyllum, after removal of low-coverage transcripts and contamination. FASTA-headers were created by TransDecoder. (ZIP 7027 kb)

Additional file 3: Longest open reading frames from major isoforms of the transcripts of Epipogium roseum, after removal of low-coverage transcripts and contamination. FASTA-headers were created by TransDecoder. (ZIP $5621 \mathrm{~kb}$ )

Additional file 4: Longest open reading frames from major isoforms of the transcripts of Hypopitys monotropa, after removal of low-coverage transcripts and contamination. FASTA-headers were created by TransDecoder. (ZIP $6215 \mathrm{~kb}$ )

Additional file 5: Figure S1. Statistics regarding contamination in the studied transcriptomes. A total of 10,000 random transcripts (prior to the removal of low-coverage transcripts and searching for ORFs, but after the removal of minor isoforms) were taken from each assembly, and BLASTX alignment to NCBI NR (maximum allowed e-value of 10-5, word size of 3 amino acids, low-complexity sequence filter switched off) was performed. The transcripts were classified according to their best matches. In the distribution plots, the black lines denote median values, and the boxes denote interquartile ranges. (TIFF $1124 \mathrm{~kb}$ )

Additional file 6: Figure S2. Diagram of circadian rhythms regulation. (TIFF 967 kb) 
Additional file 7: Figure S3. Diagram of carotenoid biosynthesis. (TIFF 563 kb)

Additional file 8: Figure S4. Diagram of ubiquinone and other terpenoid-quinone biosynthesis. (TIFF $422 \mathrm{~kb}$ )

Additional file 9: Figure S5. Diagram of thiamine metabolism. (TIFF 234 kb) Additional file 10: Figure S6. Trees of the studied species with branch lengths representing $\mathrm{dS}$ (rate of synonymous substitutions). (TIFF $134 \mathrm{~kb}$ )

Additional file 11: Figure S7. Trees of the studied species with branch lengths representing $\mathrm{dN}$ (rate of non-synonymous substitutions). (TIFF $274 \mathrm{~kb}$ )

Additional file 12: Figure S8. Trees of the studied species with branch lengths representing dN/dS. (TIFF $330 \mathrm{~kb}$ )

\section{Abbreviations}

bps: Base pairs; CDS: Coding sequence; FPKM: Fragments per kilobase per million reads mapped; GO: Gene ontology; HGT: Horizontal gene transfer; HMM: Hidden Markov model; kbps: Kilobase pairs; KEGG: Kyoto Encyclopedia of Genes and Genomes; NCBI: National Center for Biotechnology Information; ORF: Open reading frame; TAIR: The Arabidopsis Information Resource; SA: Transcriptome Shotgun Assembly Database

\section{Acknowledgements}

The authors would like to thank Viktoria Shtratnikova for helpfu discussion, Tatiana Neretina and the staff of Kandalaksha State Reserve for E. aphyllum specimen, Maxim Nuraliev for E. roseum specimen and Alexey Kondrashov for $\mathrm{H}$. monotropa specimen; Elena Zvyagina, Maxim Nuraliev and Natalia Pankova - for the permission of the use of their photos. Also, we would like to thank the reviewers for valuable comments.

\section{Funding}

This study was supported by Russian Science Foundation (project \# 1450-00150 - sequencing and analysis of Epipogium transcriptomes, project \# 17-14-01315 - sequencing and analysis of Hypopitys transcriptomes).

\section{Availability of data and materials}

The datasets generated during the current study are available in the NCBI repository, https://www.ncbi.nlm.nih.gov/bioproject/PRJNA330626.

\section{Authors' contributions}

MIS performed the computational analysis and drafted the manuscript. AAP participated in sequencing, discussion and writing. MDL sequenced the samples and participated in discussion and manuscript writing. All authors have read and approved the manuscript

\section{Ethics approval}

E. aphyllum is a protected species in Russia; it was collected under permission from Kandalaksha State Reserve (agreement \#2011_31). E. roseum was collected during the expedition approved by the Joint Russian-Vietnamese Tropical Scientific and Technological Center. H. monotropa is not rare and/or endangered plant in the area of its collection thus no permission is required.

\section{Consent for publication}

Not applicable.

\section{Competing interests}

The authors declare that they have no competing interests.

\section{Publisher's Note}

Springer Nature remains neutral with regard to jurisdictional claims in published maps and institutional affiliations.

\section{Author details}

${ }^{1}$ Institute for Information Transmission Problems, Russian Academy of Sciences, Moscow, Russia. ${ }^{2}$ A.N Belozersky Institute of Physico-Chemical Biology, Lomonosov Moscow State University, Moscow, Russia. ${ }^{3}$ Faculty of Biology, Lomonosov Moscow State University, Moscow, Russia. ${ }^{4}$ Skolkovo Institute of Science and Technology, Moscow, Russia. ${ }^{5}$ Extreme Biology
Laboratory, Institute of Fundamental Medicine and Biology, Kazan Federal University, Kazan, Russia.

Received: 10 January 2018 Accepted: 30 July 2018

Published online: 09 August 2018

\section{References}

1. Merckx V, Bidartondo Ml, Hynson NA. Myco-heterotrophy: when fungi host plants. Ann Bot. 2009:104:1255-61.

2. Westwood JH, Yoder JI, Timko MP, de Pamphilis CW. The evolution of parasitism in plants. Trends Plant Sci. 2010;15:227-35.

3. Yang Z, Wafula EK, Honaas LA, Zhang H, Das M, Fernandez-Aparicio M, et al. Comparative transcriptome analyses reveal core parasitism genes and suggest gene duplication and repurposing as sources of structural novelty. Mol Biol Evol. 2015:32:767-90.

4. Kim G, LeBlanc ML, Wafula EK, de Pamphilis CW, Westwood JH. Plant science. Genomic-scale exchange of mRNA between a parasitic plant and its hosts. Science. 2014;345:808-11.

5. Bellot S, Cusimano N, Luo S, Sun G, Zarre S, Gröger A, et al. Assembled plastid and mitochondrial genomes, as well as nuclear genes, place the parasite family Cynomoriaceae in the Saxifragales. Genome Biol Evol. 2016;8:2214-30.

6. Li X, Zhang T-C, Qiao Q, Ren Z, Zhao J, Yonezawa T, et al. Complete chloroplast genome sequence of holoparasite Cistanche deserticola (Orobanchaceae) reveals gene loss and horizontal gene transfer from its host Haloxylon ammodendron (Chenopodiaceae). PLoS One. 2013;8:e58747.

7. Yang Z, Zhang Y, Wafula EK, Honaas LA, Ralph PE, Jones S, et al. Horizontal gene transfer is more frequent with increased heterotrophy and contributes to parasite adaptation. Proc Natl Acad Sci U S A. 2016;

8. Bellot S, Renner SS. The plastomes of two species in the endoparasite genus Pilostyles (Apodanthaceae) each retain just five or six possibly functional genes. Genome Biol Evol. 2015;8(1):189-201.

9. Barrett CF, Freudenstein JV, Li J, Mayfield-Jones DR, Perez L, Pires JC, et al. Investigating the path of plastid genome degradation in an earlytransitional clade of heterotrophic orchids, and implications for heterotrophic angiosperms. Mol Biol Evol. 2014;31:3095-112

10. Lim GS, Barrett CF, Pang C-C, Davis J. Drastic reduction of plastome size in the mycoheterotrophic Thismia tentaculata relative to that of its autotrophic relative Tacca chantrieri. Am J Bot. 2016;103:1129-37.

11. Schelkunov MI, Shtratnikova WY, Nuraliev MS, Selosse M-A, Penin AA Logacheva MD. Exploring the limits for reduction of plastid genomes: a case study of the mycoheterotrophic orchids Epipogium aphyllum and Epipogium roseum. Genome Biol Evol. 2015;7:1179-91.

12. Wicke S, Muller KF, de Pamphilis CW, Quandt D, Wickett NJ, Zhang Y, et al. Mechanisms of functional and physical genome reduction in photosynthetic and nonphotosynthetic parasitic plants of the broomrape family. Plant Cell. 2013:25:3711-25.

13. Smith DR, Lee RW. A plastid without a genome: evidence from the nonphotosynthetic green algal genus Polytomella. Plant Physiol. 2014; 164:1812-9

14. Molina J, Hazzouri KM, Nickrent D, Geisler M, Meyer RS, Pentony MM, et al. Possible loss of the chloroplast genome in the parasitic flowering plant Rafflesia lagascae (Rafflesiaceae). Mol Biol Evol. 2014;31:793-803.

15. Smith DR, Asmail SR. Next-generation sequencing data suggest that certain nonphotosynthetic green plants have lost their plastid genomes. New Phytol. 2014:204(1):7-11.

16. Fan W, Zhu A, Kozaczek M, Shah N, Pabón-Mora N, González F, et al. Limited mitogenomic degradation in response to a parasitic lifestyle in Orobanchaceae. Sci Rep. 2016;6:36285.

17. Wickett NJ, Honaas LA, Wafula EK, Das M, Huang K, Wu B, et al. Transcriptomes of the parasitic plant family Orobanchaceae reveal surprising conservation of chlorophyll synthesis. Curr Biol. 2011;21:2098-104.

18. Logacheva MD, Schelkunov MI, Shtratnikova VY, Matveeva MV, Penin AA. Comparative analysis of plastid genomes of non-photosynthetic Ericaceae and their photosynthetic relatives. Sci Rep. 2016;6:30042.

19. Ravin NV, Gruzdev EV, Beletsky AV, Mazur AM, Prokhortchouk EB, Filyushin $M A$, et al. The loss of photosynthetic pathways in the plastid and nuclear genomes of the non-photosynthetic mycoheterotrophic eudicot Monotropa hypopitys. BMC Plant Biol. 2016;16:153-61.

20. Zhang J, Ruhlman TA, Mower JP, Jansen RK. Comparative analyses of two Geraniaceae transcriptomes using next-generation sequencing. BMC Plant Biol. 2013;13:228. 
21. Bolger AM, Lohse M, Usadel B. Trimmomatic: a flexible trimmer for Illumina sequence data. Bioinformatics. 2014;30:2114-20.

22. Grabherr MG, Haas BJ, Yassour M, Levin JZ, Thompson DA, Amit I, et al. Fulllength transcriptome assembly from RNA-Seq data without a reference genome. Nat Biotechnol. 2011;29:644-52.

23. Haas BJ, Papanicolaou A, Yassour M, Grabherr M, Blood PD, Bowden J, et al. De novo transcript sequence reconstruction from RNA-seq using the trinity platform for reference generation and analysis. Nat Protoc. 2013;8:1494-512.

24. Li B, Dewey CN. RSEM: accurate transcript quantification from RNA-Seq data with or without a reference genome. BMC Bioinformatics. 2011;12:323.

25. CLC Assembly Cell. Available from: https://www.qiagenbioinformatics.com/ products/clc-assembly-cell/

26. Camacho C, Coulouris G, Avagyan V, Ma N, Papadopoulos J, Bealer K, et al. BLAST+: architecture and applications. BMC Bioinformatics. 2009;10:421.

27. Parra G, Bradnam K, Korf I. CEGMA: a pipeline to accurately annotate core genes in eukaryotic genomes. Bioinformatics. 2007;23:1061-7.

28. Berardini TZ, Reiser L, Li D, Mezheritsky Y, Muller R, Strait E, et al. The arabidopsis information resource: Making and mining the "gold standard" annotated reference plant genome: Tair: Making and Mining the "Gold Standard" Plant Genome. Genesis. 2015;53:474-85.

29. Conesa A, Götz S, García-Gómez JM, Terol J, Talón M, Robles M. Blast2GO: a universal tool for annotation, visualization and analysis in functional genomics research. Bioinform Oxf Engl. 2005;21:3674-6.

30. Kanehisa M, Sato Y, Morishima K. BlastKOALA and GhostKOALA: KEGG tools for functional characterization of genome and metagenome sequences. J Mol Biol. 2016;428:726-31.

31. Li L, Stoeckert CJ, Roos DS. OrthoMCL: identification of ortholog groups for eukaryotic genomes. Genome Res. 2003;13:2178-89.

32. Gene Ontology database. [cited 2015 Apr 15]. Available from: http://purl. obolibrary.org/obo/go/go-basic.obo

33. Yekutieli $D$, Benjamini $Y$. The control of the false discovery rate in multiple testing under dependency. Ann Stat. 2001;29:1165-88.

34. Abascal F, Zardoya R, Telford MJ. TranslatorX: multiple alignment of nucleotide sequences guided by amino acid translations. Nucleic Acids Res. 2010;38:W7-13.

35. Edgar RC. MUSCLE: multiple sequence alignment with high accuracy and high throughput. Nucleic Acids Res. 2004;32:1792-7.

36. Angiosperm Phylogeny Website, version 14. [cited 2015 Sept 23]. Available from: http://www.mobot.org/MOBOT/research/APweb/

37. Yang Z. PAML 4: phylogenetic analysis by maximum likelihood. Mol Biol Evol. 2007;24:1586-91.

38. Emanuelsson O, Nielsen H, Brunak S, von Heijne G. Predicting Subcellular localization of proteins based on their $\mathrm{N}$-terminal amino acid sequence. J Mol Biol. 2000;300:1005-16.

39. Saravanan V, Velan LP. Dualpred: a webserver for predicting plant proteins dual-targeted to chloroplast and mitochondria using split proteinrelatedness-measure feature. Curr Bioinforma. 2015:10:323-31.

40. Mitschke J, Fuss J, Blum T, Höglund A, Reski R, Kohlbacher O, et al. Prediction of dual protein targeting to plant organelles. New Phytol. 2009;183:224-36.

41. Finn RD, Coggill P, Eberhardt RY, Eddy SR, Mistry J, Mitchell AL, et al. The Pfam protein families database: towards a more sustainable future. Nucleic Acids Res. 2016:44:D279-85.

42. Finn RD, Clements J, Arndt W, Miller BL, Wheeler TJ, Schreiber F, et al. HMMER web server: 2015 update. Nucleic Acids Res. 2015;43:W30-8.

43. Eddy SR. Profile hidden Markov models. Bioinform Oxf Engl. 1998;14:755-63.

44. Stöver BC, Müller KF. TreeGraph 2: combining and visualizing evidence from different phylogenetic analyses. BMC Bioinformatics. 2010;11:7.

45. Kanehisa M, Sato Y, Kawashima M, Furumichi M, Tanabe M. KEGG as a reference resource for gene and protein annotation. Nucleic Acids Res. 2016;44:D457-62.

46. Rasmussen HN. Terrestrial orchids from seed to mycotrophic plant. Cambridge; New York: Cambridge University Press; 1995.

47. Chang W, Schulman AH. BARE retrotransposons produce multiple groups of rarely polyadenylated transcripts from two differentially regulated promoters. Plant J. 2008:56:40-50

48. Shiina T, Tsunoyama Y, Nakahira Y, Khan MS. Plastid RNA polymerases, promoters, and transcription regulators in higher plants. Int Rev Cytol. 2005;244:1-68.

49. Stengel A, Benz JP, Buchanan BB, Soll J, Bölter B. Preprotein import into chloroplasts via the toc and tic complexes is regulated by redox signals in Pisum sativum. Mol Plant. 2009;2:1181-97.
50. Huang M, Friso G, Nishimura K, Qu X, Olinares PDB, Majeran W, et al. Construction of plastid reference proteomes for maize and Arabidopsis and evaluation of their orthologous relationships; the concept of Orthoproteomics. J Proteome Res. 2013;12:491-504.

51. Tanz SK, Castleden I, Hooper CM, Vacher M, Small I, Millar HA. SUBA3: a database for integrating experimentation and prediction to define the SUBcellular location of proteins in Arabidopsis. Nucleic Acids Res. 2013;41:D1185-91.

52. Zampini É, Truche S, Lepage É, Tremblay-Belzile S, Brisson N. Plastid Genome Stability and Repair. In: Li X-Q, editor. Somat Genome Var Anim Plants Microorg. Hoboken: Wiley; 2017. p. 119-63. [cited 2018 Jun 19] Available from. https://doi.org/10.1002/9781118647110.ch7.

53. Wu C-S, Chaw S-M. Evolutionary stasis in cycad Plastomes and the first case of Plastome GC-biased gene conversion. Genome Biol Evol. 2015;7:2000-9.

54. Li F-W, Kuo L-Y, Pryer KM, Rothfels CJ. Genes translocated into the plastid inverted repeat show decelerated substitution rates and elevated GC content. Genome Biol Evol. 2016;8:2452-8.

55. Ruhlman TA, Zhang J, Blazier JC, Sabir JSM, Jansen RK. Recombinationdependent replication and gene conversion homogenize repeat sequences and diversify plastid genome structure. Am J Bot. 2017;104:559-72.

56. Kikuchi S, Bedard J, Hirano M, Hirabayashi Y, Oishi M, Imai M, et al. Uncovering the protein translocon at the chloroplast inner envelope membrane. Science. 2013;339:571-4.

57. de Vries J, Sousa FL, Bölter B, Soll J, Gould SB. YCF1: a green TIC? Plant Cell. 2015;27:1827-33.

58. Nakai M. The TIC complex uncovered: The alternative view on the molecular mechanism of protein translocation across the inner envelope membrane of chloroplasts. Biochim Biophys Acta. 1847;2015:957-67.

59. Nakai M. YCF1: a green TIC: response to the de Vries et al. Commentary Plant Cell. 2015;27:1834-8.

60. Bjorkman E. Monotropa Hypopitys L. - an Epiparasite on tree roots. Physiol Plant. 1960;13:308-27.

61. Taylor L, Roberts DL. Biological Flora of the British Isles: Epipogium aphyllum Sw.: Epipogium aphyllum Sw. J Ecol. 2011;99:878-90.

62. Yagame T, Yamato M, Mii M, Suzuki A, Iwase K. Developmental processes of achlorophyllous orchid, Epipogium roseum: from seed germination to flowering under symbiotic cultivation with mycorrhizal fungus. J Plant Res. 2007;120:229-36.

63. Karamoko M, Cline S, Redding K, Ruiz N, Hamel PP. Lumen Thiol Oxidoreductase1, a disulfide bond-forming catalyst, is required for the assembly of Photosystem II in Arabidopsis. Plant Cell. 2011;23:4462-75.

64. Mubarakshina MM, Ivanov BN. The production and scavenging of reactive oxygen species in the plastoquinone pool of chloroplast thylakoid membranes. Physiol Plant. 2010;140:103-10.

65. Nosek M, Kornaś A, Kuźniak E, Miszalski Z. Plastoquinone redox state modifies plant response to pathogen. Plant Physiol Biochem. 2015:96:163-70.

66. Rock CD, Zeevaart JA. The aba mutant of Arabidopsis thaliana is impaired in epoxy-carotenoid biosynthesis. Proc Natl Acad Sci U S A. 1991:88:7496-9.

67. Nievelstein V, Vandekerchove J, Tadros MH, Lintig JV, Nitschke W, Beyer P. Carotene desaturation is linked to a respiratory redox pathway in Narcissus pseudonarcissus chromoplast membranes. Involvement of a $23-\mathrm{kDa}$ oxygen-evolving-complex-like protein. Eur J Biochem. 1995;233:864-72.

68. Cummings MP, Welschmeyer NA. Pigment composition of putatively achlorophyllous angiosperms. Plant Syst Evol. 1998;210:105-11.

69. Tanaka A, Tanaka R. Chlorophyll metabolism. Curr Opin Plant Biol. 2006;9: 248-55.

70. Hirashima M, Tanaka R, Tanaka A. Light-independent cell death induced by accumulation of pheophorbide a in Arabidopsis thaliana. Plant Cell Physiol. 2009;50:719-29.

71. Hedges SB, Marin J, Suleski M, Paymer M, Kumar S. Tree of life reveals clocklike speciation and diversification. Mol Biol Evol. 2015;32:835-45.

72. Bromham L, Hua X, Lanfear R, Cowman PF. Exploring the relationships between mutation rates, life history, genome size, environment, and species richness in flowering plants. Am Nat. 2015;185:507-24.

73. Bromham L, Cowman PF, Lanfear R. Parasitic plants have increased rates of molecular evolution across all three genomes. BMC Evol Biol. 2013;13:126.

74. Logacheva MD, Schelkunov MI, Nuraliev MS, Samigullin TH, Penin AA. The plastid genome of mycoheterotrophic monocot Petrosavia stellaris exhibits both gene losses and multiple rearrangements. Genome Biol Evol. 2014;6:238-46.

75. Gharib WH, Robinson-Rechavi M. The branch-site test of positive selection is surprisingly robust but lacks power under synonymous substitution saturation and variation in GC. Mol Biol Evol. 2013;30:1675-86. 
76. Tiller N, Bock R. The translational apparatus of plastids and its role in plant development. Mol Plant. 2014;7:1105-20.

77. Jansen RK, Saski C, Lee S-B, Hansen AK, Daniell H. Complete plastid genome sequences of three rosids (Castanea, Prunus, Theobroma): evidence for at least two independent transfers of rpl22 to the nucleus. Mol Biol Evol. 2011; 28:835-47.

78. Park S, Jansen RK, Park S. Complete plastome sequence of Thalictrum coreanum (Ranunculaceae) and transfer of the rpl32 gene to the nucleus in the ancestor of the subfamily Thalictroideae. BMC Plant Biol. 2015;15:40.

79. Ueda M, Fujimoto M, Arimura S, Murata J, Tsutsumi N, Kadowaki K. Loss of the rpl32 gene from the chloroplast genome and subsequent acquisition of a preexisting transit peptide within the nuclear gene in Populus. Gene. 2007:402:51-6.

80. Kubo N, Arimura S-I. Discovery of the rpl10 gene in diverse plant mitochondrial genomes and its probable replacement by the nuclear gene for chloroplast RPL10 in two lineages of angiosperms. DNA Res. 2010;17:1-9.

81. Ueda M, Nishikawa T, Fujimoto M, Takanashi H, Arimura S-I, Tsutsumi N, et al. Substitution of the gene for chloroplast RPS16 was assisted by generation of a dual targeting signal. Mol Biol Evol. 2008;25:1566-75.

82. Matasci N, Hung L-H, Yan Z, Carpenter EJ, Wickett NJ, Mirarab S, et al. Data access for the 1,000 plants (1KP) project. GigaScience. 2014;3:17.

Ready to submit your research? Choose BMC and benefit from:

- fast, convenient online submission

- thorough peer review by experienced researchers in your field

- rapid publication on acceptance

- support for research data, including large and complex data types

- gold Open Access which fosters wider collaboration and increased citations

- maximum visibility for your research: over $100 \mathrm{M}$ website views per year

At BMC, research is always in progress.

Learn more biomedcentral.com/submissions 